Dr. F. J. Garessien, Milwaukee, Wis,: I have nothing to add, except that, in the preparation of the artificial limb, the socket for the stump consists of a heavy sole-leather cap, which is scarcely more than a quarter of an inch in thickness. As a result there is, in sitting, only a minimal difference in length of thighs. In the present instance the increase in length was negligible.

\section{A STUDY OF THE END-RESULTS OF THE BALDY-WIBSTER OPERATION *}

\author{
JOIIN OSIBORN POLAK, M.D., M.Sc. \\ BROOKLYN
}

In this bricf paper, which is based on a personal experience of over 4.00 cases, I shall attempt to draw conclusions from the end-results of the Baldy-Webster operation.

\section{TIIIS IPINCIPLES OF UTEIRINE SUPPOR'}

'The uterus is a freely movalble organ and is suspended in the pelvis between the abdominal cavity and the pelvic floor by the harmonious action of all of its supports; that is:

'The pelvic floor.

'The adjacent pelvic organs.

The retentive power of the abslominal cavity (intra-abdominal pressure).

The several ligaments.

linally, by the normal relation which the uterine axis bears to the axis of the vagina.

The axis of the utcrus with the bladder and rectum moderately full conforms with the axis of the pelvis, and is nearly at a right angle with that of the vagina. With the bladder empty, the axis of the vagina is almost horizontal and runs almost directly backward, while the uterus is directed forward at an acute angle.

Normally, the fundus of the uterus is at or a little above the level of the pelvic brim, while the inferior

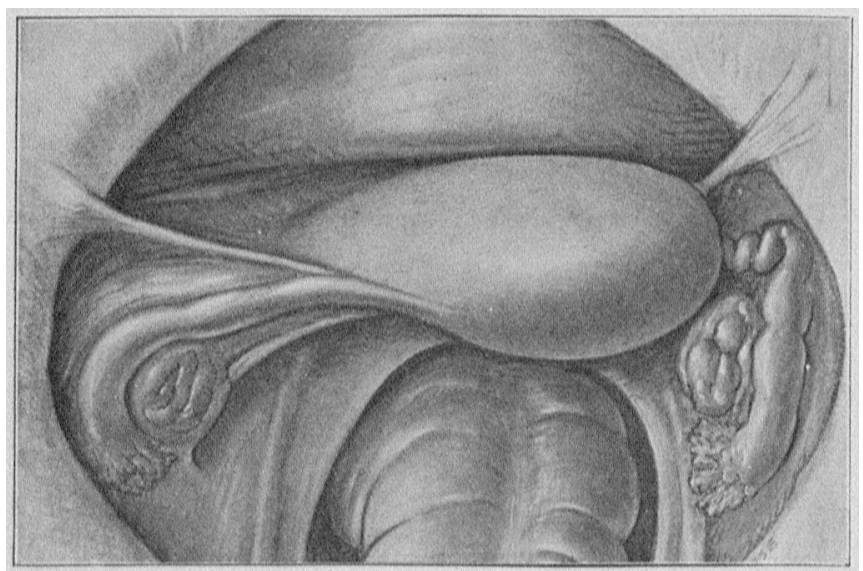

Fig. 1.-Tateral version of the uterus.

extremity of the uterus, the cervix, projects into the vagina and is directed toward the last sacral vertebra. With all the adjacent pelvic structures in their normal state, the cervix is more or Jess a fixed point, lying in the plane of the ischial spines, a little posterior to the center of the pelvis. 'The cervix is held in this position by the utcropelvie ligaments and the nterosacral ligaments and the vesicovaginal fascial plate; the body rests on the pulic shell.

* lecud in the section on Olestetples, Gynecology nud Abdominal Suryery of the Amerienn Modlend Assochation, at the sixty-Fourt Annual Sesston, held at Minnetapolss, June, 1913.
The normal axis of the aterus has a wide range of inclination, depending on the degree of fulness of the bladder and rectum; the uterus moves upward and down. ward with ench r'espiratory excursion and changes its position with that of the body.

\section{TITS ACTION OF ITS SUPPORTING LIGAMEN'IS}

The nteropelvic ligaments consist of bands of muscle fibers running outward from the supravaginal portion of the cervix to the pelvic fascia, within the base of each broad ligament; they prevent the uteriss from undergoing lateral changes in position and help materially in

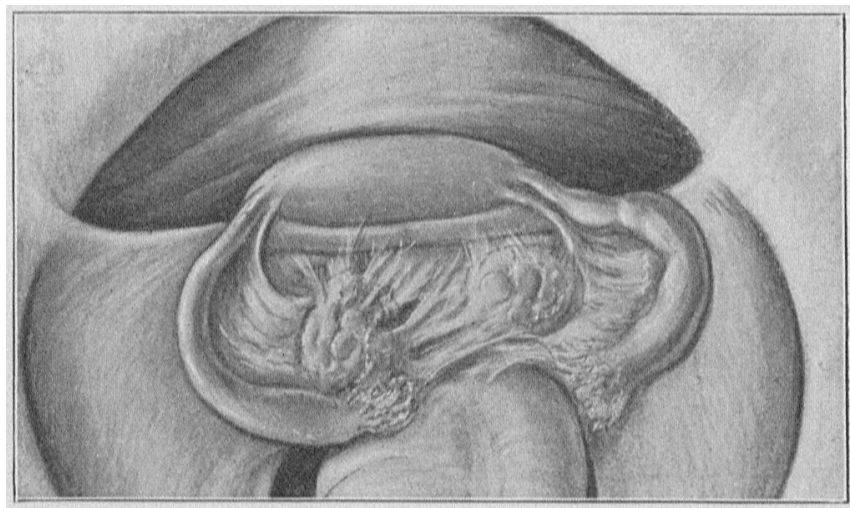

Fig. 2.-Ovilies adherent to one another and thrown upward and inward by heavy uterus slipping out of sling.

preventing uterine prolapse. The broad ligaments act in some measure to steady the uterus in or near the median section of the pelvis. 'The uterosacral ligaments pull the cervix backward and upward, thus tending to antevert the body, while the round ligaments act as stays or "guyropes" to draw the uterus forward and prevent it from falling backward. The round ligaments are muscular bands covered with peritoneum.

WIIAT THE JBALDY-WBIBSTIS OP'SRATION DOES

The Baldy-Welster operation elevates the uterus and its adnexa and holds the fundus forward. This is accomplished, according to Baldy, by three forces:

1. 'The intra-abdominal pressure on the posterior fundal wall.

2. The encircling band formed by the round ligaments.

3. The downward pull of the round ligaments on the uterine cornua.

In this operation the uterus is upehld by the encircling loop of the round ligament which is sutured to the posterior surface of the body, in a line just below the level of insertion of the utero-ovarian ligament. 'L'he ovaries and fallopian tubes rest free of broad ligament attachment on the round ligaments, as they pass through the broad and uncler the ntero-ovarian digaments.

'The perf'ect col'rertion of a retrodeviation of the nterus by this operation must therefore ilepend on the following conditions:

1. A cervix held backward and upward by well-developed uterosacrals.

2. A good pelvic floor to preserve the position and integrity of all of the pelvic organs.

3. $A$ uterus of molerate sime and weight, and round ligaments of equal dength and thickness which can be made to encircle tho uterus.

'The technical diffieulties of the operation are for the most part insignificant, yet they are present. 


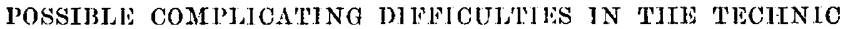

Clinically, we find that the round ligmments are frequently unequally developed in length, thickness, and in muscular tone; this is commonly so post partmm, when the retroversion or flexion is associated with subinvolution, descensus and pelvice injury. The use of such ligaments for the Baldy-Webster operation must necessarily produce a lateral version of the uterus, and this las been an end-result too often noted (Fig. 1).

Varicosities of the veins of the pampinifurm plexus are common to all retrodisplacements with descensus.

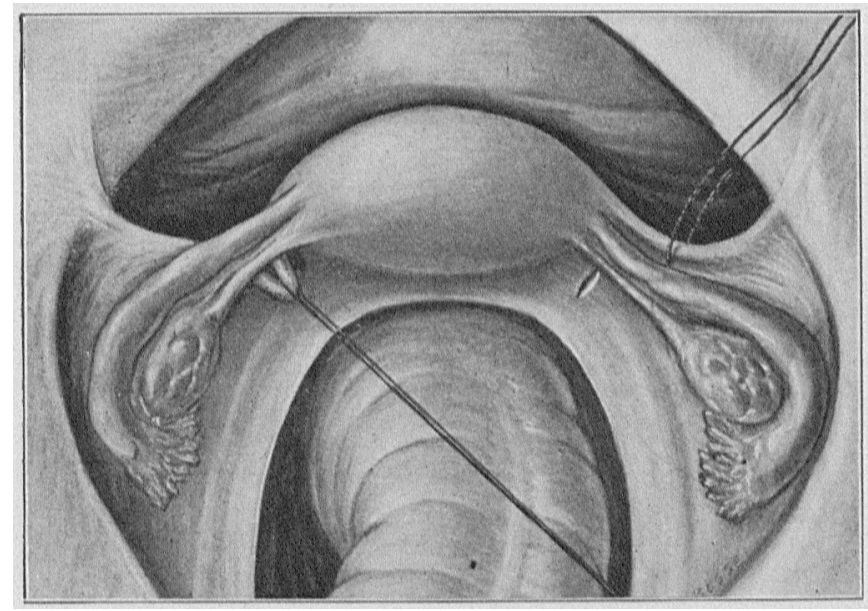

Fig. 3.-Author's technic.

The passage of the round ligament through the opening made for it by blunt dissection in the broad ligament may injure these veins of the utero-ovarian anastomosis and give rise to troublesome bleeding, the control of which by ligature may further interfere with the venous circulation, or even produce a thrombophlebitis which may extend from the pelvis to the femoral or the saphenous vein. 'I'lurombosis has been relatively more frequent following this operation than after other procedures on the round liganents.

Strangulation of a portion of the ligament which has been drawn behind the uterus is not uncommon, and has occasioned in several instances a local peritonitis. Congenital or aequired adhesion of the sigmoid to the posterior surface of the broad ligament may complicate the technic by relatively shortening the ligament on that side.

Unless the ligaments are liastened low enough on the posterjor nterine wall, i.e., just below the level of the utero-ovarian insertion, there is a tendency for the ovaries to be carricel upward and to be thrown over forward with the rolling forward of the broad ligaments; they may even be rolled into the anterior peritoneal pouch, while if the attachment is too low, the ligaments serve as a loop over which the body may bend, making a retroflexion out ol a retroversion.

'l'orsion of the ligaments is a common crror in technic, the jmportance of which is apparently not appreciated by many operators; this always gives rise to swelling from olstuction to the circulation of the ligament, and local peritonitis with more or less extensive local adbesions. I believe that the severe inguinal pain noted following some of these operations may be attributed to this cause.

Jo the erities who state that the Baldy-Webster operation puts a strain on the weakest part of the ligament, i.e., the portion nearest the inguimal canal, I would state that this operation does not elaim to suspend the uterus by supporting or lumging it by the round ligaments, as does the Gilliam, but simply draws the fundus forward, and if the cervix is well back and firmly held there by the uterosacrals, intra-abdominal pressure will retain the organ in anteversion.

ITS NWHCT ON THE POSIIION OF THE OVARIES

The ovaries are elevated by this operation. 'This is accomplished in the following mammer:

1. By the general elevation and anteversion of the uterus.

2. By the grolling forward of the top of the broad ligament, owing to the pull backward of the round ligament as it passes through the hole in the broad ligament. 'The patency of the tubes, if free from adhesions, is not interfered with by this disposition of the round ligument.

In almost all cases of retroversion of long standing there are varicosities of the broad ligments, and changes in the size, position and histology of the ovaries, which result in prolapse, thickened stroma and cystic degeneration, making it imperative, in order to secure a symptomatic cure, that the basic causes as well as the position be corrected, i.e., that the pelvic circulation be equalized, not obstructed. In the ideal case in which the uterus is not too heavy, the ovaries and tubes are normal and the cervix is held well back toward the sacrum by its sup. ports; j.c., the uterosacral and the uteropelvic ligaments. Shortening the round ligaments by eneircling the uterus with the Joop of the round ligament meets all of the claims of its originators; but when the uterus is heavy, the round ligaments attenuated or unequally developed, and the cervix points forward, either because of congenital malformation, or as a result of the stretching of the uterosacral ligaments, the uterus will fall into lateral version or sag in the pelvis. What really takes place when the uterus sags may be illustrated by attempting to lift a small boy by placing your arms under his axillae

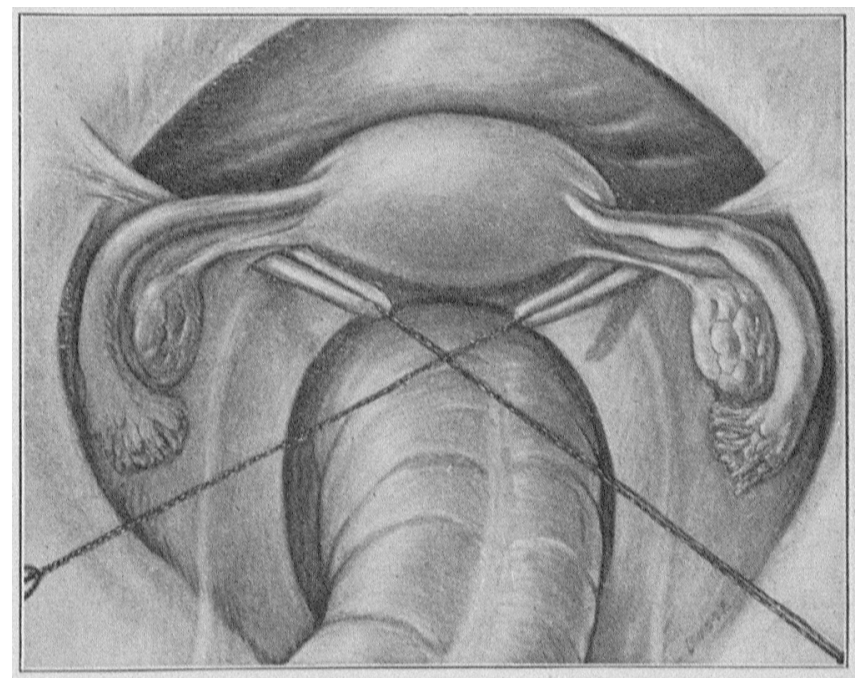

rig. 4.-A uthor's technic.

and cmbracing him with your forearms. He can't get away except by sliding from your embrace by raising his arms. So the uterus slides out of the encircling band down into the pelvis, raising the ovaries and throwing them inward toward the median line, where they may become adherent to one another, behind and above the ligamentous sling (1)ig. 2).

Yet no operation for retroversion of the uterus seems to meet the indications so perfectly as does this one of Baldy's, when all conditions are fuvorable. 
The technic in my clinic las been slightly varied from that described by Baldy in 1910. I have felt that grasping the ligaments with "guy-lopes" causes less trauma than catching them with clamps. Again, I have substituted a Cleveland ligature carrier for the clamp to pass through the free space below the ovarian ligament, as being less likely to injure the bloor-vessels than the Kocher forceps. I have generally spread out the loop of cach round ligament on the posterior surface of the uterus, fixing it at three points; i.e., in the median line to its fellow from the opposite side; to the ulero-ovarian ligament at the point at which the folded ligament passes

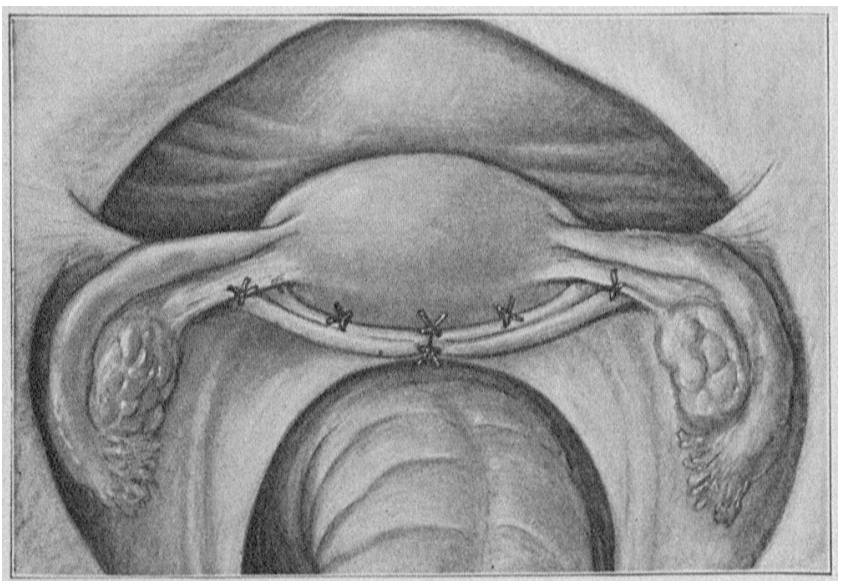

Irig. 5.-Author's technic, Sutures in place.

through the broad ligament, and to the uterine wall midway between these two points (Figs. 3, 4 and 5).

From a study of the records of the 400 operations in my clinic from Jan. 1, 1908, to Jan. 1, 1913, I make the following summary:

\section{SUMMAIY}

'Twenty-four patients have been lost track of and have not been scen by either my assistants or myself since their operation, thus leaving 376 for analysis. These women have been watched for periods varying from five months to five years and many of them have been examined repeatedly. 'Two hundred and two, or more than 50 per eent., have perfect pelves; the uterus is in its anatomic position in the pelvis and free from adnexal or parametrial inflammation. Of this number, 160 have had complete yelief of all pelvic symptoms.

'Thirty-nine having an anatomically perfect pelvis, still complain of pelvic pain, with burning sensations over the lower abdomen, and suffer from menstrual pain in the back and side.

Three have died from causes indepentent of the operation before or soon after leaving the hospital. It is among the remaining $1 \% 4$ that we find on complieations and disappointments.

Fourteen lave had secondary operations for pelvic or abdominal conditions, and the intra-abdominal patlologic conditions in each have been carefully studicd and the findings recorded. These have shown that:

1. Unequal development of the Jignments does oceur and lateral version of the uterus follows; this I bolieve to be due either to torsion of the lisament from defective terhnic, or to unequal primary development, present but unnoticed at the time of the operation.

2. Enlarged ovaries slung over the encireling band formed by the round ligaments fall lower in the pelvis by elongation of the utero-ovarian liganent and beconse allerent. 'l'sese ovaries (Fig. 6) have been cystic (mycrocystic).

3. The sigmoid is apt to become adherent to the ligamentous loops.

4. The ligaments passed behind the uterus may become comatous from constriction and offer an inflammatory surface for intestinal ardicsion.

5. When the uterus is large and sinks in the encireling loop, the ovaries are thrown upward and inward and become allherent to one another behind the uterus, forming a sensitive mass; these findings have been constant in the cases reopened; hence we would julge that some of this pathology is a cause in many unrelieved patients.

In thirty-two patients the uterus las relapsed and was found rotroverted and prolapsed, earrying the ovaries with it.

'Thinty are wearing pessaries.

Wighteen have not been benefited in any way.

Ten have lateral versions of the uterus and complain of pain in the side toward which the fundus is drawn.

Sixteen luve prolapsed and cystic ovaries.

'Two women have ovaries lying anterior to the broad Jignment.

'I'wenty-six have had thrombosis of the pelvic veins, which hais extended to the femoral and saphenous, which gives a morbidity larger than we have had from any other intra-abdominal operation.

'I'wenty women have had children subsequent to the operation.

'T'wenty-two have aborted, making in all forty-two pregnancies from which to malke observations. No complication of labor has been recorded; only one delivery has required forceps.

Fourteen of the women becoming pregnant have had great pain and discomfort during the first trimester; only four of our relapses have followed labor.

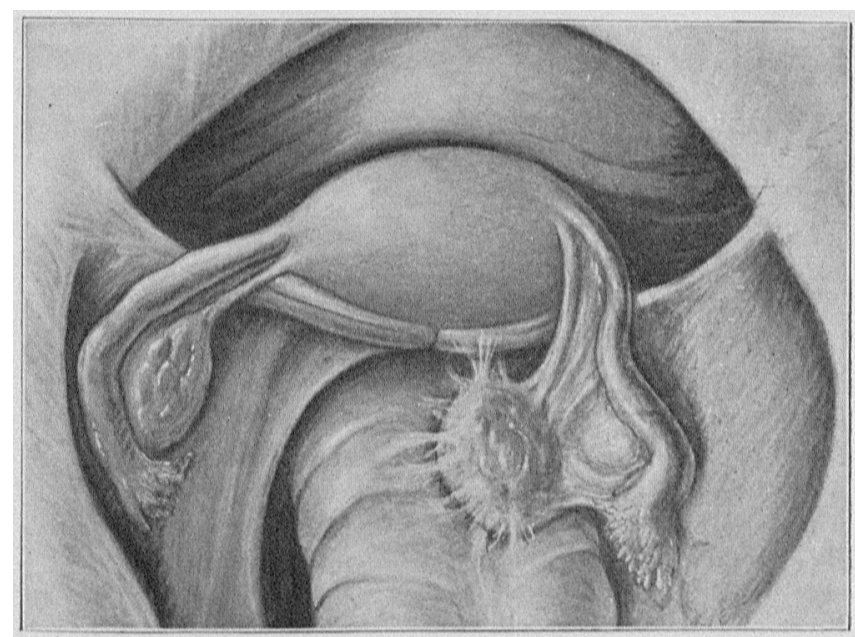

Fig. (6.-Further esongation of the utero-ovarian ligament due to enlarged ovary.

\section{CONCTUSTON}

From these observations it would scem that the BaldyWelsster operation has a definite field of usefuness in properly selected casses of retrodeviation of the uterus when intra-abilominal shortening of the round ligaments is employed. It should not be selected for heavy uteri with the eervix in the axjs of the vagina. Its success depends on a small uterus, a cervix pointing backward, equally developed ligaments and a careful technic.

287 Clinton Avemue. 


\section{ABSTRACT' OF DISCUSSION}

Dir. Edward Reynoriss, l3oston: The Webster-Bally operation is, 1 think, the best of the round-ligament operations, but I think that there is a word more to be suid. Dr. Polak has told us that the normal position of the uterus is maintained by the harmonions action of all its supports. A very important corollary is that, in the majority of cases of retroversion, the condition is due primarily to the existence of a tendency toward retroversion due to the inharmonious action eaused by an unequal development of those ligaments. The uterus is an organ which is susponded, and when it retroverts it revolves about a point which is approximately the attachment of the lases of the broal ligaments where the uterine arches approach the ecervix. A band formed by the anterior attachments draws the eervix forward and down while the nterosacral muscular structures lift the eervix upward and backward. If the Welster-Baldy or any other round ligament operation is upplied to a rase of this kind an antellexion of the fundus is created in adlition to the anteflexion of the cervix. Dr. Somers has told us that the only expedient he can see is to shorten the uterosancal ligament and pull the cervix upward and backward. 'That operation has been before the profession for many years and has not met with much favor because it is an incorrect procedure. For six years or more I have been doing an operation which I bolicve is a much better procedure. I make a trunserse incision through the nterovaginal plate, extending through the whole thickness of the unterior vaginal wall in, front of the cervix and large enouxh to admit a linger. I pass the finger in and separate the bladder from the anterior surface of the cervis and then break yp the connective tissue and museular tissue which we eall the vesieo-uterine lignments, leaving the cervix free from all the attachments which drag it forward and downward. I then bring the incision together with transverse sutures. With the Webster-Baldy operation I bring the fundus forward, and the uterosacral ligaments lift the eervix buckward.

Dr. R. S. Yanros, Chieago: I have watched the WobsterBaldy operation as done by one of its oripinators for several years, and I have seen more bad results from this one operation than from almost any other. In several cases I saw all the complications that Dr. Polak mentions. One of the cases, if I remember correctly, had three of the complications. It was a simple case of retroversion, with a slightly enlarged uterus and an enlarged ovary. The operntion was done and part of the ovary removed. 'Lwo year's afterward the woman was operated on and it was most diflieult to separate the aterus from the bladder. The result was a hysterectomy. Two other patients had to be operated on within two years, not only for discomfort, but for severe pains.

I have come to the conclusion that it is a mistake to dis. place the anatomic relations. The Webster-Baldy operation seems to me a fundamental mistake, unless it is done ns guardedly as Dr. Polak suggests. First, however, how is it possible to measure the ligaments and say that they are equal? If one is elever enough to forestall all these points no donbt the operation has a place. I am sorry that J). Webster is not here himself to sny all the good things in favor of the method, for Dr. Polak certainly did not say many things in its favor.

Dr. C. W. BARke'v', Chicugo: We are indelited to Dr. Poluk for so honestly reporting such unfavorable results. llis results have shown the evils of the operntions which were pointed out theoretically a long time ago. There lats been some question for a number of years whether the operation should be enlled the Wolsster or the Baldy operation. As a matter of fact, Dr. Baldy has about as much right to have his name attached to this operation as Cook has a right to elaim the discovery of the North Pole. There is no reason why the operation described by Dr. Welsster should be enlled the Webster-Baldy operntion.

It seems to me that these reports in regurd to the illadvisedness of this operation should be convincing to the most skepticnl individual. An ubdominal operation must be safe and simple; it must allow inspeetion of the contents of the ablomen; all of these requirements this operation does to a certain extent fulfil, except that of safety. 'Then it must use natural ligaments instend of false ligaments and must use the strongest part of the round ligament. The round ligament grows smaller and smaller toward the internal ring, and any operation that throws out the two-thirds of the anterior portion of the ligament throws out the very best part of the ligament we have for holding the uterus forward.

DR. J. O. Por.AK, New York: This discussion has brought out just what I had hoped it would bring out--the results of some of the other observers. I felt that perhaps my results were due to faulty techuic or a misconception of the prin(-iples of the operation, but they liave been reported to you fairly. Dr. Reynolds made the point that anomalies of the uterus, such as the deep posterior invagination of the cervix. complieate retroversion work. We have found that no retroversion operation will cure putients of this class permanently. unless the cervix is placed and held bnckward toward the sacrum. I brought this point out some six years ago in a paper which J presented to the American Gynecological Society on the result of suspension of the nterus. It was only by the use of a pessary immediately after our suspension operations ware done that we were able to present such excellent results in restoration of the nterus-results not obtained by other men with this operation. This was not because of the technie, but beenuse we recognized that the cervix must be kept lackward, and that, if this was done, the fundus would be maintaned forward by intra-abdominal pressure. The pessury in a large number of cases did this mechanienl act.

I am sorry that I gave the impression that I huve condemned the Webster-J3aldy operation. I have not. I am still using it occasionally, but am selecting the cases. These four hundred cases include all degrees of retroversion. We were doing the Webster-13aldy operation on the cases in which we removed a tube or an ovary or in which we were doing struight retroversion work. We are now selecting for this operation the small uterus with well-developed round ligaments, with few, if any, varicosities in the broad ligaments, and with a cervix that is not congenitally anteflexed.

\section{IS MEMBRANOUS DYSMENORRIIEA CAUSED BY ENIOMETRITIS *}

\author{
K. I. SANISS, M.D. \\ PITTSBURG, PA.
}

In this paper J shall use the term "menstrual membrane" insteal of membranous dysmenorrhen because we are interested in all the membranes passed during the menstrual period, and since not all are acempanied by pain, the term "membranous dysmenorrhea" canmot cover them all. I shall use the term "membranous dysmenorrhea" only when 1 wish to convey the idea of a membrne passed with pain. Bofore taking up the question of the relation of the menstrual membrane to endometritis, it is essential to consider the histology of the enclometrium.

\section{JISTOLOGY OF WNDOMLTIIUM}

The desceliption of the endometrim as given by the anatomists is not muiform. In the old deseription the endometrium was considered as a definite and unchangeable structure. The pieture of the endometrium most commonly met was consiclered to be the normal one and any deviation from it was looked on as pathologic.

* Read in the saction on obstritries. Gynccology and Aludominal Surrely of the Amerienn Arcalcal Associntlon, in the Slxty-Fourth Annual Sesslon, Leld at Mimncapolls, Junc, 1013. 